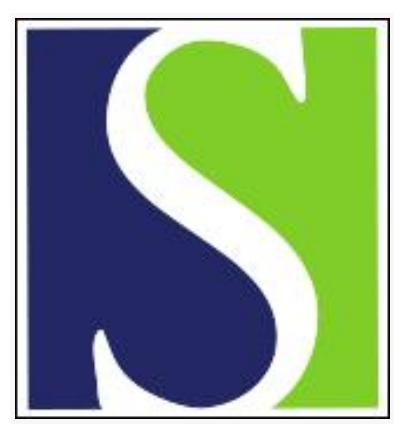

Scand J Work Environ Health 1980;6(1):40-47

https://doi.org/10.5271/sjweh.2635

Issue date: Mar 1980

Irreversible effects of trichloroethylene exposure on the central nervous system.

by Kjellstrand P, Lanke J, Bjerkemo M, Zetterqvist L, Månsson L

The following articles refer to this text: 1986;12(2):154-155;

1985;11(6):495-497

Key terms: behavior; central nervous system; exposure; irreversible effect; maze; spatial memory; trichloroethylene; trichloroethylene exposure

This article in PubMed: www.ncbi.nlm.nih.gov/pubmed/7384766 


\title{
Irreversible effects of trichloroethylene exposure on the central nervous system
}

\author{
by $\mathrm{P}$ Kjellstrand, J Lanke, M Bjerkemo, L Zetterqvist, L Månsson '
}

\begin{abstract}
KJELLSTRAND P, LANKE J, BJERKEMO M, ZETTERQVIST L, MANSSON L. Irreversible effects of trichloroethylene exposure on the central nervous system. Scand $j$ work environ health 6 (1980) 40-47. Mongolian gerbils (Meriones Unguiculatus) were continuously exposed to $320 \mathrm{ppm}\left(1.72 \mathrm{~g} / \mathrm{m}^{3}\right)$ of trichloroethylene (TCE) for nine months. During this period the spatial memory of the animals was tested. No major differences were found between the TCE group and the air-exposed control group. Eleven days after the end of TCE exposure, the animals were again tested. Every second day during this test, they were exposed to $2,300 \mathrm{ppm}\left(12.6 \mathrm{~g} / \mathrm{m}^{3}\right)$ of $1,1,1-\operatorname{trich}$ loroethane for $6 \mathrm{~h}$. It was found that, on days when exposed to 1,1,1-trichloroethane, the animals previously exposed to TCE made more correct choices in the maze than on days when not exposed, whereas the control group made less. This test was repeated $75 \mathrm{~d}$ after the end of TCE exposure. The results were predominantly the same as $11 \mathrm{~d}$ after TCE exposure. The results are interpreted as showing that irreversible effects on the central nervous system are caused by exposure to $320 \mathrm{ppm}\left(1.72 \mathrm{~g} / \mathrm{m}^{3}\right)$ of TCE during nine months. The effects cannot be directly observed as changes in the behavior of the animals but can be revealed in almost every single animal by treatment with 1,1,1-trichloroethane. The possibility that covert toxicologic effects might exist in humans exposed to volatile solvents and that the effects may be unmasked by alcohol, stress, or age is discussed.
\end{abstract}

Key terms: behavior, central nervous system, exposure, maze, spatial memory, trichloroethylene.

The lipid solubility of volatile solvents is generally presumed to cause acute central nervous system (CNS) depression by impairing the permeability of the nerve cell membrane and the neural transmission (11, $18,19)$. The mechanism by which volatile solvents causes chronic nervous damage is, however, obscure. Moreover, there is no single and common type of chronic effect, but an entire spectrum of probable or known impairments in both the central and peripheral nervous systems. Thus the mechanisms could be multiple.

1 Department of Zoophysiology and Department of Mathematical Statistics, University of Lund, Lund, Sweden.

Reprint requests to: $\mathrm{P}$ Kjellstrand, Department of Zoophysiology, University of Lund, Helgonavägen $3 \mathrm{~B}, \mathrm{~S}-22362$ Lund, Sweden.
Trichloroethylene (TCE) has been reported to cause various symptoms in humans exposed for long periods $(12,26)$. In general such symptoms have been reported to disappear when the subject is removed from exposure. There is increasing evidence of a connection between long-term exposure to moderate concentrations of volatile solvents and chronic damage to the CNS $(1,10)$. Thus, although there is no firm experimental support, there is reason to believe that TCE might alone - or even more probably in combination with other solvents - cause permanent damage to the CNS, if the time of exposure is long enough.

Long-time exposure studies necessarily involve long periods. Thus it is hardly possible for the epidemiologist to obtain adequate purity in exposure or adequate con- 
trols for groups of people exposed at work. Therefore, to obtain basic knowledge on long-term toxicology, one probably has to resort to animal experiments, and, as the CNS is probably the most sensitive target, to behavioral experiments. However, animal experiments involving long-time exposure and behavioral studies are scarce 12, 25). Furthermore, the experiments mostly probe only the effects of long-term inhalation and do not include adequate postexposure periods for the removal of the solvent metabolites. Thus the chronic aspect of the effect is lost.

The concentration at which the first effects of long-time exposure on the CNS appear seems quite close to the concentration at which short-time exposure effects can be detected $(2,3,7,8,20,21)$. The reason for this somewhat unexpected circumstance may be either that no long-term effects develop at lower concentrations or that such effects are concealed. This last explanation is highly probable and should not be overlooked; it is known that parts of the CNS have a remarkable capacity for compensating damage, at least for meshanical injury. Thus both in experimental animals and in humans "covert damage" might occur (5) which represents damage undetected by the tests used. Such damage might be revealed by more sensitive methods, by ageing (which indeed could be disastrous to man), or, as was the basic idea in this study, by an increase in the load on the CNS through the introduction, after the end of long-term exposure, of another substance which would supposedly cause a depression of the CNS. In this study we have directed our interest to these problems, using TCE for the longtime exposure and 1,1,1-trichloroethane $(1,1,1)$ for the postexposure.

\section{Material and methods}

\section{Animals}

Fifteen-month-old Mongolian gerbils (Meriones Unguiculatus) weighing 70$120 \mathrm{~g}$ were used for the experiments. The animals were housed in pairs in makrolon cages $(24 \times 45 \times 15 \mathrm{~cm})$. Commercial laboratory rat chow (AB Astra Evos, Sweden) (6) and water were available ad libitum. Females and males were paired at least four weeks before the onset of exposure to the solvent. During the first phase of the investigation, 12 TCE-exposed and 12 air-exposed pairs, thus 48 animals in all, were used; during the latter phases only eight of the TCE-exposed and eight of the air-exposed animals took part. Sawdust provided bedding, and woodwool nesting. The temperature was $22 \pm$ $3^{\circ} \mathrm{C}$. Light supplementing daylight was controlled automatically: $12 \mathrm{~h}$ of daylight and $30 \mathrm{~min}$ of twilight at dawn and evening.

The animals were weighed once weekly during the experiment and were, due to this handling, quite tame already at the beginning of the training with the eightarmed maze.

\section{Exposure unit}

Exposure to TCE was conducted in approximately cubical $0.15 \mathrm{~m}^{3}$ inhalation chambers with three sides of glass. Four animal cages, each containing one pair of animals, were placed in each inhalation chamber. Each chamber was provided with approximately 12 I of $\mathrm{air} / \mathrm{min}$. Commercial trichloroethylene (TCE), stabilized with $100 \mathrm{ppm}\left(146 \mathrm{~g} / \mathrm{m}^{3}\right)$ of thymol and $300 \mathrm{ppm}\left(437 \mathrm{~g} / \mathrm{m}^{3}\right)$ of diisopropylamine (manufactured by Uddeholm AB, Skoghall, Sweden) was used during the study. The solvent was injected at a known rate into a temperature-controlled glass vaporizer. The vaporized solvent was mixed with a small volume of air, which was subsequently diluted with clean air to give the desired concentration. All air was filtered to remove oil and particles down to $0.3 \mu$. The concentration in the chambers was monitored continuously with a Miran 1A (Wilks Scientific Corp.) infrared spectrophotometer with multipath gas cell. The long-time stability of the system permitted the concentration of solvent to be held within $10 \%$ of the desired level. The differences in different locations inside the exposure chambers were within $10 \% 1 \mathrm{~h}$ after exposure began. Interruptions were made 1-2 $\mathrm{h}$ per week for change of water, bedding material, and food.

\section{The maze}

The spatial memory of the animals was tested in a symmetrical maze, earlier 
described by Olton and co-workers $(13,14$, $15,16,17,27)$. Two versions of the maze were used, one with 8 and one with 16 arms. The maze consisted of a central platform with symmetrically attached arms. During the tests, each arm was baited with a sunflower seed. The animals were then placed on the central platform and allowed to make a certain number of choices among the arms; this number was eight in the case of the eight-armed maze and 16 in the other case. An arm was considered as visited when the animal had passed a small barrier near the end of the arm. A correct choice was defined as a visit to an arm which had not previously been entered and which thus still contained a sunflower seed. After some training, the gerbils searched the maze for seeds with great accuracy and speed. Between different animals' visits, the maze was cleaned with a vacuum cleaner. The room in which the experiments were conducted was well illuminated and contained a variety of objects.

\section{Exposure and testing schedule}

But for the visits to the maze and the interruptions already mentioned, TCE exposure was continuous at $320 \mathrm{ppm}$ (172 $\mathrm{g} / \mathrm{m}^{3}$ ) for nine months (272 d). During this period, starting after two months of exposure (at day 59), the eight-armed maze experiment was performed. The animals were trained for two weeks and then tested each day for two weeks. Training was performed in the same way as the testing, except that no notations were made. Weekends were free from training and testing.

The eight-armed maze turned out to be too easily solved by the gerbils and was therefore replaced by a 16-armed one during the later tests.

The first experiment with the 16-armed maze began with training for five weeks before the end of TCE exposure and ended after nine weeks. The last $4 \mathrm{~d}$ of TCE exposure were test days. Beginning on day
11 after the end of TCE exposure, the animals were exposed every second day to $2,300 \mathrm{ppm}\left(12.6 \mathrm{~g} / \mathrm{m}^{3}\right)$ of 1,1,1-trichloroethane. The exposure lasted $6 \mathrm{~h}$ on every occasion and was begun $3 \mathrm{~h}$ before the maze testing. Weekends were free from testing and exposure. There were ten testing occasions.

The second test with the 16-armed maze was started 2.5 months ( $75 \mathrm{~d}$ ) after the end of TCE exposure. This test was identical with the first, except that a total of 12 tests were performed with each animal; it was preceded by one week of training.

\section{Statistical methods}

It should be observed that when, eg, each of 16 animals is tested on $4 \mathrm{~d}$, we do not have 64 statistically independent observations; an animal which is above average on the first day is likely to be so on the following days as well. In such situations one had better first form, for each animal, the average over the $4 \mathrm{~d}$ and then use the 16 averages as a basis for the additional statistical treatment. In all tests reported, we have followed this procedure.

Except for Fisher's exact test for $2 \times 2$ tables, which was used to show that TCEexposed animals react differently than air-exposed ones when exposed to $1,1,1$, all statistical tests reported are t-tests either ordinary or paired, as the situation called for. As is well known, a t-test requires the quantities involved to be normally distributed, or at least approximately so. Since averages are known to be more normally distributed than individual observations, we feel confident that t-tests have been used appropriately in our investigation, and we have not considered it worthwhile to use any distribution-free alternatives such as the Wilcoxon rank sum test or its paired counterpart, the Wilcoxon signed rank test.

All tests reported are two-tailed tests, $i e$, the $p$-value is given as twice the tail probability of the event observed.

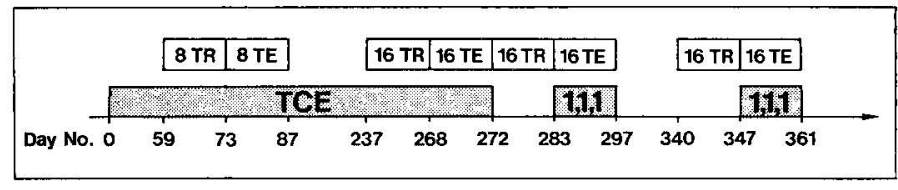

Fig 1. Exposure and testing schedule. 


\section{Results}

Test with the eight-armed maze after two months of trichloroethylene exposure

During the first of the two test weeks with the eight-armed maze, when the number of correct responses was still increasing, the mean number of correct responses in the air-exposed group (24 animals) was higher than that in the TCEexposed group (24 animals). The difference was not statistically significant, nor was there any difference during the second week when the number of correct responses had almost stabilized in both groups. The only significant difference found $(\mathrm{p}<1 \%$ ) was that the average time needed (two test weeks) for the airexposed group to make eight choices (118 s) was shorter than that of the TCE-exposed group (137 s). There was no difference in the number of seeds eaten.

Test with the 16-armed maze after nine months of trichloroethylene exposure

Before being tested in the 16-armed maze, the 16 animals taking part were trained as in the eight-armed maze experiment. The first test took place during the last $4 \mathrm{~d}$ of the TCE treatment. As was the case in the previously mentioned test with the eight-armed maze, the air-exposed group made more correct choices than the TCEexposed group. The means were 13.2 and 13.7, respectively, out of 16 for the two groups; again the differences were not statistically significant. There was no difference in the time needed for the 16 visits or in the number of seeds consumed.
Test with the 16-armed maze after 11 days of rehabilitation

Eleven days after the end of TCE exposure a test was begun during which all the animals were exposed to $1,1,1$ for $6 \mathrm{~h}$ every second day. Comparisons of two different types could be made: (i) between TCE-exposed and air-exposed animals on $1,1,1$, days and, similarly, on non-1,1,1 days; (ii) between 1,1,1 days and non-1,1,1 days for TCE-exposed animals and, similarly, for air-exposed animals. The results are summarized in table 1.

Influence of previous trichloroethylene exposure. The number of correct choices, the number of seeds eaten, and the time needed for the 16 arm visits showed no statistically significant differences between the TCE-exposed group and the air-exposed group, neither on 1,1,1 days nor on days free from $1,1,1$.

Influence of 1,1,1-trichloroethane exposure. For each of the two groups, exposure to $1,1,1$ gave a statistically significant effect; as far as the number of correct choices and the number of seeds consumed are concerned, these differences are, however, in different directions in the TCE-exposed and air-exposed groups.

In the TCE-exposed group, the animals made, on the average, more correct choices on days when exposed to $1,1,1$ than on days free from $1,1,1(p<5 \%)$, while those in the air-exposed group made fewer $(p<1 \%)$. The number of seeds consumed followed the same pattern $(\mathrm{p}<5 \%$ and $\mathrm{p}<1 \%$, respectively). The time needed to complete the 16 arm visits decreased in both groups when they were exposed to

Table 1. Average number of correct choices, consumed seeds, and time spent for the first 16 arm visits in the experiment with the 16-armed maze $11 \mathrm{~d}$ after the end of trichloroethylene (TCE) exposure. The column - 1,1,1 gives averages from days when the animals were not exposed to $1,1,1$-trichloroethane, and $+1,1,1$ shows averages from days when they were. Each average is based on eight animals, each tested five times.

\begin{tabular}{|c|c|c|c|c|c|c|}
\hline & \multicolumn{3}{|c|}{ TCE-exposed group } & \multicolumn{3}{|c|}{ Air-exposed group } \\
\hline & $-1,1,1$ & $+1,1,1$ & $p$ & $-1,1,1$ & $+1,1,1$ & $\mathrm{p}$ \\
\hline $\begin{array}{l}\text { Correct choices } \\
\text { Consumed seeds } \\
\text { Time (s) }\end{array}$ & $\begin{array}{r}13.0 \\
12.6 \\
272\end{array}$ & $\begin{array}{r}13.6 \\
13.0 \\
228\end{array}$ & $\begin{array}{l}<0.05 \\
<0.05 \\
<0.01\end{array}$ & $\begin{array}{r}13.7 \\
12.5 \\
242\end{array}$ & $\begin{array}{r}12.9 \\
11.3 \\
204\end{array}$ & $\begin{array}{l}<0.01 \\
<0.01 \\
<0.01\end{array}$ \\
\hline
\end{tabular}


$1,1,1$ ( $p<1 \%$ in both groups; $p<0.1 \%$ if the groups are pooled).

Some comment might be in order about our ability to demonstrate differences in the case of 1,1,1 exposure, while not being able to do so for TCE exposure only. Table 1 shows that in the TCE group the average number of correct choices was 13.0 and 13.6 on non-1,1,1 days and 1,1,1 days, respectively, while the corresponding numbers for the control group were 13.7 and 12.9. As previously stated, the differences $13.0-13.7$ and 13.6-12.9 are not significantly different than zero, while the differences 13.6-13.0 and $12.9-13.7$ are. The reason for this is that in the first case different animals were involved in the two means being compared, while in the second the two means were formed for the same animals, the situation being a paired-comparison one.

The data concerning the influence of $1,1,1$ can be treated in another way as well. In the TCE-exposed group seven animals out of eight made, on the average, more correct choices when exposed to $1,1,1$ than otherwise, while one animal made fewer. In the control group seven out of eight made fewer and one made exactly the same number of correct choices. The application of Fisher's exact test (twotailed version) to a $2 \times 2$ table with rows 7,1 and 0,7 , respectively, gives $p<1 \%$. If we treat the data on the number of seeds consumed in the same way, we get a table with rows 6,1 and 0,7 , again giving $p<1 \%$. - It should perhaps be pointed out that, statistically speaking, there is a slight difference between what, on one hand, we just demonstrated using Fisher's exact test and what, on the other, we previously showed using a paired t- test. By means of the t-test we showed that 1,1,1 affected both the TCE animals and the air-exposed animals; the Fisher test showed that 1,1,1 had different effects on the TCE animals and the air-exposed ones. Of course the latter point is by far the more interesting one.

Test with the 16-armed maze after 75 days of rehabilitation

A new test run was started $75 \mathrm{~d}$ after the end of TCE exposure. The results are summarized in table 2.

Influence of previous trichloroethylene exposure. The number of different arms visited, the number of seeds consumed, and the time needed for the 16 arm visits did not differ significantly between the TCEexposed group and the air-exposed one, neither on 1,1,1 days nor on the non-1,1,1 days.

Influence of 1,1,1-trichloroethane exposure. In both the TCE group and the airexposed one, the number of correct choices and the number of seeds consumed was influenced by $1,1,1$ in the same way as in the test after $11 \mathrm{~d}$ of rehabilitation. In the present test, however, the differences in question were significant only in the air-exposed group ( $p<5 \%$ for both comparisons). The time needed to complete the 16 arm visits decreased in the air-exposed group ( $p<1 \%$ ) but not in the TCE group.

In the TCE group six animals out of eight made more correct choices on 1,1,1 days than otherwise, while two animals made fewer. In the air-exposed group seven animals made fewer correct choices

Table 2. Average number of correct choices, consumed seeds, and time spent for the first 16 arm visits in the experiment with the 16-armed maze $75 \mathrm{~d}$ after the end of trichloroethylene (TCE) exposure. The column - 1,1,1 gives averages from days when the animals were not exposed to $1,1,1$-trichloroethane, and $+1,1,1$ shows averages from days when they were. Each average is based on eight animals, each tested seven times $(-1,1,1)$ or six times $(+1,1,1)$.

Correct choices

Consumed seeds

Time (s)

\begin{tabular}{|c|c|c|c|c|c|}
\hline \multicolumn{3}{|c|}{ TCE-exposed group } & \multicolumn{3}{|c|}{ Air-exposed group } \\
\hline$-1,1,1$ & $+1,1,1$ & $p$ & $\longrightarrow 1,1,1$ & $+1,1,1$ & $p$ \\
\hline 13.7 & 14.0 & - & 14.1 & 13.0 & $<0.05$ \\
\hline 13.2 & 13.6 & $<0.10$ & 13.1 & 12.0 & $<0.05$ \\
\hline 232 & 232 & - & 248 & 214 & $<0.01$ \\
\hline
\end{tabular}


and one made more. The $2 \times 2$ table with rows 6,2 and 1,7 showed a significant $(p<5 \%)$ difference between the two groups. The corresponding table for the number of seeds consumed had rows 6,2 and 2, 6 and showed no significant difference between the groups.

\section{Discussion}

Both at the test two months after the beginning of TCE exposure, at the end of the nine-month period and after 11 and $75 \mathrm{~d}$ of rehabilitation, only slight effects of the TCE exposure were seen as long as the behavior of the animals was tested without any additional treatment. This finding agrees with earlier published results from experiments with other species, including man, at concentrations of about $200-400 \mathrm{ppm}\left(1-2 \mathrm{mg} / \mathrm{m}^{3}\right)(23,24,26)$. From these studies the conclusion has been drawn that TCE has no effects at these concentrations (12).

The introduction of $1,1,1$ into the testing scheme strikingly changes this picture. Not only are differences between the behavior of the TCE- and air-exposed animals seen, but it is possible to reveal the effect of TCE on almost every single animal and, at that, not only on the average over days but, in many cases, on individual days as well. In fig 2 we have, for every animal and every 1,1,1 day, indicated whether the animal's performance was better, equally good, or worse than on the immediately preceding non-1,1,1 day. The hypothesis that TCE-exposed animals make more correct choices when exposed to $1,1,1$ whereas the air-exposed controls react in the opposite way was, as can be seen from the figure, verified on $55 \%$ and opposed on only $15 \%$ of the testing occasions. The females were, on the average, "better" than the males in this respect, verifying the hypothesis on $69 \%$ and opposing it on $11 \%$ of the testing occasions. (As already pointed out, the observations cannot be considered statistically independent, and thus it would not be appropriate to perform, eg, a sign test.) The difference between the males and females may of course be due to true differences in sensitivity to TCE, but another explanation seems equally at hand: body volume, especially body fat, might act as a buffer to the acute effects of $1,1,1$ exposure (4), and, as great differences exist between males and females in this respect, one explanation for the sex differences is that the effect of TCE is the same on both sexes but not as easily revealed in the males as in the females by the experimental system.

The results presented pose several questions. The most important is how the results can be applied to man. Nothing is positively known about this application because the mechanisms of solvent action are not understood. But it is well known that compounds toxic for one species tend to be so for others $(9,26)$. Other important questions are how fast the irreversible effects develop in our experiments and whether they do so at lower concentrations. Work is proceeding to clarify these points. Finally, we question whether the
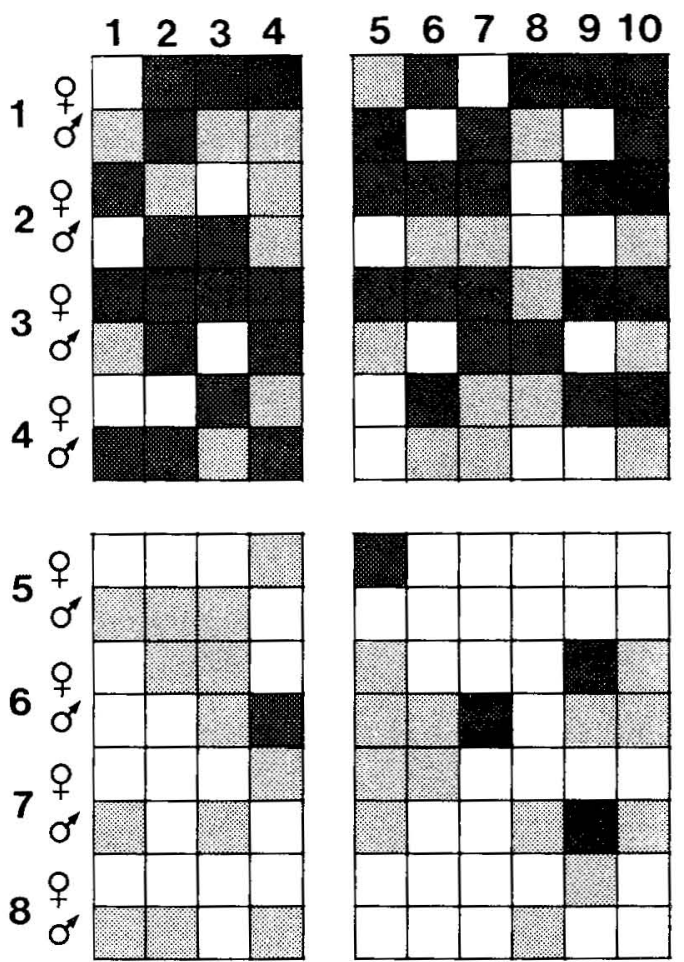

Fig 2. Individual performance during days (110) when exposed to 1,1,1-trichloroethane compared with individual performance during the preceding day free from 1,1,1-trichloroethane exposure $11 \mathrm{~d}(1-4)$ and $75 \mathrm{~d}(5-10)$ after the end of trichloroethylene (TCE) exposure. Pairs 1-4 were exposed to TCE and $5-8$ were unexposed controls. 
observed effects are specific to TCE and $1,1,1$. The existence of such phenomena as the "degreasers flush" (22) makes it highly probable that other solvents or combinations of solvents could produce the same effects. Perhaps the "uncovering factor" which has to be introduced to reveal the effects of the long-term TCE exposure need not necessarily be a solvent; alcohol (which, in the meaning under consideration, is not thought of as a solvent), stress, or increasing age, might be sufficient. Thus the feeling that a discrepancy exists between results from the clinical testing (under well-controlled and stressfree conditions) of subjects thought to be adversely affected by solvents and their actual life situation, where feedback reactions between alcohol, stress, and psychosocial factors could easily develop, might have an explanation in the presented findings.

\section{Acknowledgment}

Grants from the Swedish Work Environment Fund supported this work.

\section{References}

1. Axelson O, Hane M, Hogstedt C. A casereferent study on neuropsychiatric disorders among workers exposed to solvents. Scand j work environ health 2 (1976) 14 -20 .

2. Baettig $\mathrm{K}$. Comparison of the effects of trichloroethylene with the effects of drugs on exploratory behavior in the rat. In: International congress on occupational health, 14th, Madrid. Vol 2. 1964, pp 887-889.

3. Baettig K, Grandjean E. Chronic effects of trichloroethylene on rat behavior. Arch environ health 7 (1963) 694-699.

4. Bergman $K$. Application of whole-body autoradiography to distribution studies of organic solvents. In: International symposium on the control of air pollution in the working environment, Stockholm, 6-8 Sept 1977. Part II. The Work Environment Fund, Stockholm 1977, pp 128-139.

5. Bowman RE. Preclinical behavioral toxicology of inhalant solvents. NIDA research monograph 15 (1977) 200-223.

6. Flodh H, Magnusson G, Magnusson O. Pulmonary foam cells in rats of different age. Z Versuchstierkd 16 (1974) 299-312.

7. Grandjean E. Trichloroethylene effects on animal behaviour. Arch environ health 1 (1960) 106-108.

8. Grandjean E. The effects of short exposures to trichloroethylene on swimming performances and motor activity of rats. Am ind hyg assoc j 24 (1963) $376-379$.

9. Hiatt V, Huff JE. The environmental impact of cadmium: An overview. Int $\mathrm{j}$ environ stud 7 (1975) 277-285.

10. Knave B, Persson HE, Golberg JM, Westerholm P. Long-term exposure to jet fuel: An investigation on occupationally exposed workers with special reference to the nervous system. Scand $\mathrm{j}$ work environ health 2 (1976) 152-164.

11. Lowe HJ, Hagler K. Determination of volatile organic anesthetics in blood, gases, tissues and lipids: Partition coefficients. In: Ported R, ed. Ciba Foundation symposium gas chromatography in biology and medicine. J. London and A. Churchill Ltd. London 1969, p 86.

12. National Institute for Occupational Safety and Health. Criteria for a recommended standard... Occupational exposure to trichloroethylene. Rockville, MD 1973. (Report no. NIOSH-TR-043-73. NTIS PB-222222).

13. Olton DS. Spatial memory. Sci am 236 (1977) 82-98.

14. Olton DS, Branch M, Best P. Spatial correlates hippocampal unit activity. Exp neurol 58 (1978) $387-409$.

15. Olton DS, Collison C, Werz MA. Spatial memory and radial maze performance of rats. Learn motiv 8 (1977) 289-314.

16. Olton DS, Samuelson RJ. Remembrance of places: Spatial memory in rats. $J$ exp psychol anim behav process 2 (1976) 97-116.

17. Olton DS, Walker JA, Gage FH. Hippocampal connections and spatial discrimination. Brain res 139 (1978) 295-309.

18. Prockop L, Couri D. Nervous system damage from mixed organic solvents. Natal inst drug abuse res monogr ser 15 (1977) 185-198.

19. Seeman P. Membrane stabilization by drugs: Tranquilizers, steroids and anesthetics. Int rev neurobiol 9 (1966) 145-221.

20. Silverman AP, Williams H. Behaviour of rats and the threshold limit value of trichloroethylene: Environ pollut 3 (1975) $1601-1603$.

21. Silverman AP, Williams $H$. Behaviour of rats exposed to trichloroethylene vapor. $\mathrm{Br} \mathrm{j}$ ind med 32 (1975) $308-315$.

22. Stewart RD, Hake CL, Peterson JE. "Degreasers' flush": Dermal response to trichloroethylene and ethanol. Arch environ health 29 (1974) $1-5$.

23. Stewart RD, Hake CL, Lebrun AJ, Kalbfleisch JH, Newton PE, Peterson JE, Cohen $\mathrm{HH}$, Struble R, Busch KA. Effects of trichloroethylene on behavioral performance capabilities. In: Xintaras C, Johnson BL, de Groot I, ed. Behavioral toxicology, early detection of occupational hazards. University of Cincinnati, Cincinnati, $\mathrm{OH}$ 1974, pp 96-129. (NTIS PB-259 322).

24. Stewart RD, Hake CL, Peterson JE, Forster HV, Newton PE, Soto RJ, Lebrun AJ. Development of biologic standards for trichloroethylene. In: Xintaras C, Johnson 
BL, de Groot I, ed. Behavioral toxicology, early detection of occupational hazards. University of Cincinnati, Cincinnati, $\mathrm{OH}$ 1974, pp 81-91. (NTIS PB-259 322).

25. Waters EM, Black SA. Trichloroethylene: II. An abstracted literature collection 1907 -1976. Toxicology Information Response Center, National Library of Medicine, Oak Ridge National Laboratory, Oak Ridge, TN 1976. (ORNL/TIRC-76/2.)
26. Waters EM, Gerstner HB, Huff JE. Trichloroethylene: I. An impact overview. Toxicology Information Response Center, National Library of Medicine, Oak Ridge National Laboratory, Oak Ridge, TN 1976. (ORNL/TIRC-76/2).

27. Zoladek L, Roberts WA. The sensory basis of spatial memory in the rat. Anim learn behav 6 (1978) $77-81$.

Received for publication: 1 October 1979 